\title{
Research on the Source Mechanism and Source Prevention and Control System of Deep Rock Burst
}

\author{
Shuai Di \\ Information Research Institute of the Ministry of Emergency Management, Beijing 100029, China \\ Correspondence should be addressed to Shuai Di; 1150563280@qq.com
}

Received 8 May 2020; Accepted 31 July 2020; Published 4 September 2020

Academic Editor: Francesco Colangelo

Copyright (c) 2020 Shuai Di. This is an open access article distributed under the Creative Commons Attribution License, which permits unrestricted use, distribution, and reproduction in any medium, provided the original work is properly cited.

\begin{abstract}
Deep rock burst accidents occur frequently and become increasingly serious. Further improving the effectiveness and accuracy of the prevention and control of rock burst, ensuring the safe and efficient production of mines, clarifying the basic causes of disasters, and refining the type of deep rock burst are the most important key links. Aiming at the problems such as unclear incentives and types and the lack of effective and targeted prevention measures of deep rock burst, taking Xin'an Mine as the research background, based on the energy theory, the coal and rock mass multisource energy unified equation was established to analyze coal and rock mass instability mechanism. According to the different degrees of participation of various factors, the types of deep rock burst are determined as three categories and four types, and the corresponding judgment criteria are proposed. The precise prevention and control system for the source of rock burst with Xin'an characteristics is proposed, successfully applied to the 8101 working face, which not only guarantees the safe production of the working face, but also achieves good economic benefits. The research results lay the foundation for improving the accuracy and precision of the prevention and control of deep rock burst and provide theoretical guidance for the safe and efficient mining of the mine.
\end{abstract}

\section{Introduction}

In recent years, safe production situation of coal mine in China has improved significantly. However, compared with other countries with developed coal mine industries, coal mine safety work still needs to be strengthened in China, especially water hazards and rock bursts. Regarding the prevention and control of water hazards, China has achieved good results [1-3]. Due to the complexity and unpredictability of the rock burst, the occurrence cannot be effectively prevented. Therefore, rock burst is one of the main power disasters faced by coal mining in China. In response to this problem, so far many experts and scholars have done lots of studies on rock burst [4-17]. Jiang et al. [4] classified rock burst into three types based on coal and rock mass failure patterns. Jiang et al. [5] classified the impact risk and type of surrounding rock according to the surrounding rock structure under external stress and the impact tendency of coal rock mass. Zhai et al. [6] pointed out the "seven modules" management technology system of rock burst with "classified governance" as the core. Pan et al. [7] have put forward three types of rock burst in deep mining from the perspective of the load source of induced rock burst based on the characteristics of deep mining rock burst in China and further proposed the prevention and control method of dynamic and static loads load of rock burst. But in recent years, most coal seams have entered deep mining; the coal seam is in a state of high in situ stress, which is more sensitive to external inflow dynamics; that is, it is prone to impact rock burst even when it is disturbed by micromovement. The complexity of the deep mining environment has led to a gradual upward trend in the frequency, intensity, scale, and damage degree of deep rock burst. Therefore, deep rock burst is still a frontier issue in domestic and foreign research. In-depth analysis of the past related accident cases was done, summarizing the causes of the accidents as the "source" mechanism of disaster occurrence is unclear and the type of disaster and the basis of judgment are insufficient, 
which affect the lack of pertinence and accuracy of prevention and control measures, resulting in the inability to completely avoid the occurrence of rock burst accidents.

Based on the above analysis, taking the 8101 working face of Xin'an Mine as the research background, a unified equation for multisource energy of coal and rock masses is established, and the types of deep rock burst are divided according to the degree of participation of various factors and corresponding judgment criteria are proposed. The precise prevention and control system for the source of rock burst with Xin'an characteristics is proposed. The above results provide a scientific basis for determining the "source" mechanism of disaster occurrence, identifying the incentives, and treating symptomatically.

\section{Mining Conditions of the Face}

The eighth mining area is located in the southwest of Xin'an Coalfield. There is a total of 3 coal seams mined, namely, $6^{\text {th }}$, $8^{\text {th }}$, and $10^{\text {th }}$. The thickness of $8^{\text {th }}$ coal seam, where the distance is $37.6 \mathrm{~m}$ away from $6^{\text {th }}$ coal seam and $33 \mathrm{~m}$ away from $10^{\text {th }}$ coal seam, is $3.6-5.9 \mathrm{~m}$. It belongs to a single coal seam with simple structure. The roof was mainly siltstone and medium-grain sandstone, and the floor was mainly siltstone.

The LW 8101, the first deep mining face in the eighth mining area, was located in the upper part of the $6^{\text {th }}$ coal seam and the lower part of the $10^{\text {th }}$ coal seam where there is no mining activity. There is transportation to the mountain of the eight mining area on the left side and no mining activity on the right side. It was $421 \mathrm{~m}$ long and $160 \mathrm{~m}$ wide, the average thickness of coal seam was $5.85 \mathrm{~m}$, and the dip was $15.5^{\circ}$. It belongs to a more stable coal seam. The depth of overburden strata varied from $580 \mathrm{~m}$ to $660 \mathrm{~m}$. The gas content is $4.1 \mathrm{~m}^{3} / \mathrm{t}$, the absolute gas emission is $5.5 \mathrm{~m}^{3} / \mathrm{min}$, and the gas pressure is $0.34 \mathrm{MPa}$. The immediate roof was $2.65 \mathrm{~m}$ thick siltstone, the basic roof was $7.8 \mathrm{~m}$ mediumgrain sandstone, and the bottom plate was $5.0 \mathrm{~m}$ thick siltstone. According to the geological conditions revealed by roadway excavation, there are mainly fold structures in the working face.

Based on the geological and engineering technical conditions of the 8101 working face, the multifactor superposition method was used to determine the dangerous area of the working face. The results are shown in Figure 1.

Based on Figure 1, Area 1 is affected by the initial breakage of the basic roof; Area 2 is the square stage of the working face, affected by the frequent roof movement and destruction near this location; Area 3 is in the area affected by slant axis; and Area 4 is the secondary square stage of the working face, affected by roof activities and mining, while some areas are affected by slant axis.

\section{Research on the Source Mechanism of Deep Rock Burst}

Through the investigation of the current situation of deep mine rock burst in China, combined with the analysis of the case about rock burst accidents, the particularity of deep rock burst is summarized.

(1) Due to the deep burial of the coal seam, it is in a state of high in situ stress, which can easily lead to energy concentration and induce rock burst. This phenomenon is obviously different from shallow mining; that is, self-weight stress has no decisive effect on rock burst.

(2) Roof breaking not only aggravates the concentration of stress in the coal body, but also causes the sudden release of breaking energy. The coal seam under high ground stress is disturbed by nonhard roof breakage and may induce rock burst. This phenomenon is obviously different from shallow mining; that is, hard roof induces rock burst.

Therefore, the energy of deep rock burst mainly comes from the elastic energy of the coal body and the energy of overburden breaking. The key factor to clarify the "source" mechanism lies in the quantitative analysis of the energy characteristics of the evolution process in deep mining. It can provide a scientific basis for the classification of deep rock burst types and the selection of targeted prevention and control measures.

3.1. Energy Source Analysis. Establish the energy characteristic model of coal rock mass, as shown in Figure 2. Assume that the bottom plate is a rigid structure that does not deform. The energy transmitted to the working face from the overburden breaking of is $E_{d i}(i=1,2, \ldots, n)$, and the elastic energy of the coal body is $E_{m}$.

3.1.1. Transfer Characteristics of Roof Broken Energy. The overburden movement of the working face is controlled by the key layer. The initial and periodic breakage of the key layer could cause the instability of the overburden structure. The transmission of the generated energy to the working face can affect rock burst. Therefore, This is one of the key problems to be solved urgently. According to literature [17], the energy density calculation formula of the unit width key layer first and periodic broken transferred to the mining face is

$$
\begin{aligned}
& E_{\text {dinitial }}=\left[\frac{L_{1}^{5} q_{0}^{2}}{120 E h_{3}^{3}}+\frac{1}{2} g L_{1}\left(\rho_{3} h_{3}+\rho_{4} h_{4}\right)\left[h_{1}+h_{2}(1-K)\right]\right] \cdot \eta l^{-\lambda}, \\
& E_{d \text { periodic }}=\left[\frac{3 L_{1}^{5} q_{0}^{2}}{10 E h_{3}^{3}}+\frac{g L_{2}}{2}\left(\rho_{3} \mathrm{~h}_{3}+\rho_{4} \mathrm{~h}_{4}\right)\left[h_{1}+h_{2}(1-K)\right]\right] \cdot \eta l^{-\lambda},
\end{aligned}
$$

where $L_{1}$ is the first breakage step, $\mathrm{m} ; L_{2}$ is the periodic breakage step, $\mathrm{m} ; q_{0}$ is the load evenly distributed above the rock, MPa; $E$ is the elastic modulus, $\mathrm{MPa} ; \rho_{3}$ is the density of rock layer, $\mathrm{kg} / \mathrm{m}^{3} ; \rho_{4}$ is the density of upper following rock layer, $\mathrm{kg} / \mathrm{m}^{3} ; h_{3}$ is the thickness of rock layer, $\mathrm{m} ; h_{4}$ is the thickness of upper following rock layer, $\mathrm{m} ; h_{1}$ is the thickness of coal, $\mathrm{m} ; h_{2}$ is the thickness of rock layer between coal and 


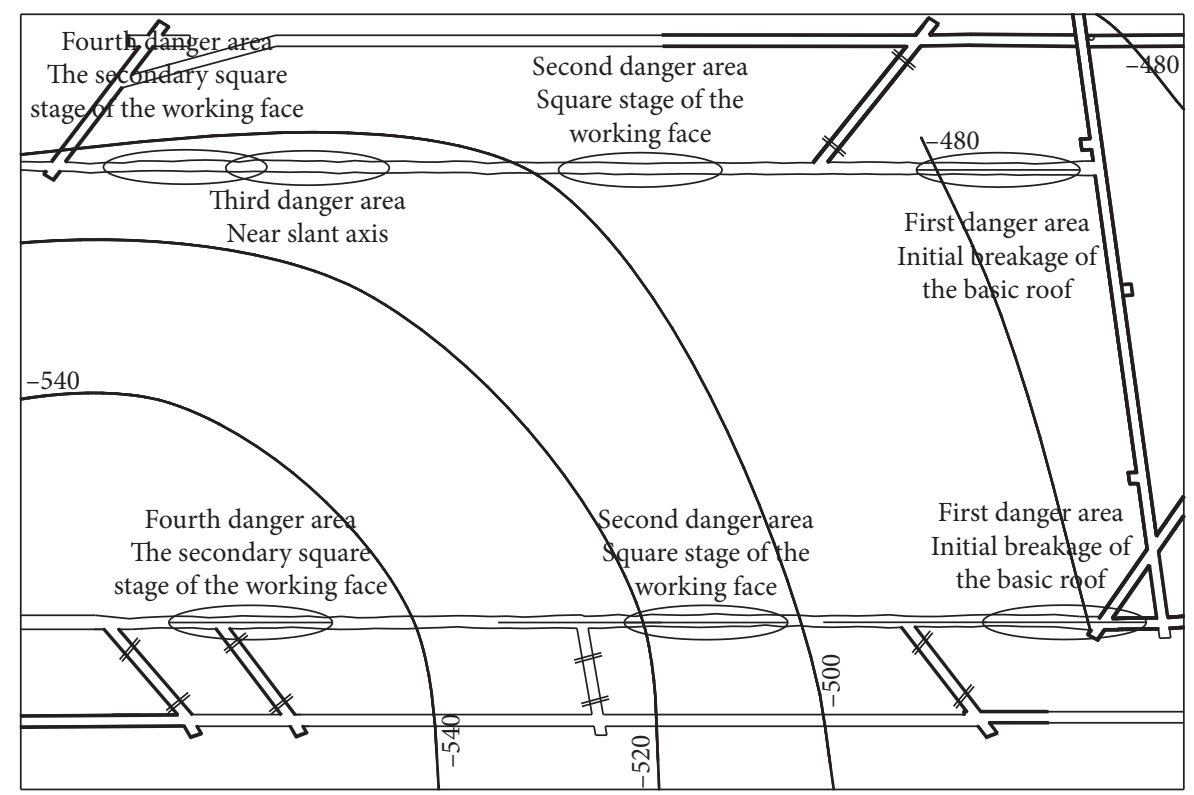

FIGURE 1: Risk area division of rock burst in LW 8101.

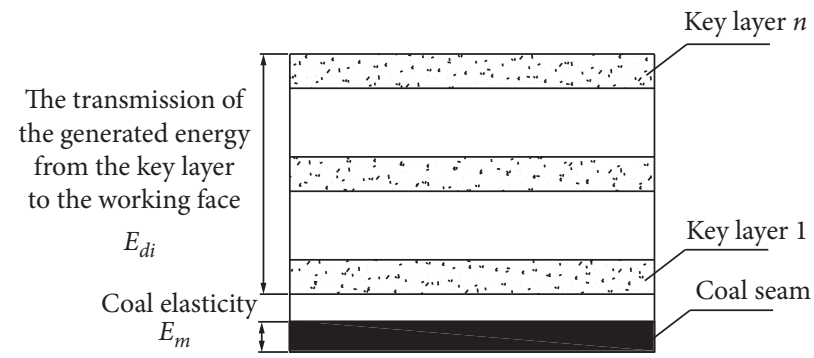

FIgURE 2: Energy characteristics model of gas coal rock mass.

key layer, $\mathrm{m}$; $K$ is the rock fragmentation expansion coefficient; $\eta$ is the ratio of vibration energy to total energy; $l$ is the distance from source to working surface, $\mathrm{m}$; and $\lambda$ is the energy attenuation coefficient.

3.1.2. Coal Elasticity. The calculation formula of the elastic strain energy accumulated in coal and rock during the coal mining process is [18]

$$
E_{m}=\frac{\left[\left(\sigma_{1}^{2}+\sigma_{2}^{2}+\sigma_{3}^{2}\right)-2 \mu\left(\sigma_{1} \sigma_{2}+\sigma_{2} \sigma_{3}+\sigma_{1} \sigma_{3}\right)\right]}{2 E},
$$

where $\mu$ is Poisson's ratio; $\sigma_{1}$ is the maximum principal stress, $\mathrm{MPa} ; \sigma_{2}$ is the intermediate principal stress, $\mathrm{MPa}$; and $\sigma_{3}$ is the minimum principal stress, MPa.

3.2. Energy Consumption Analysis. The process of coal and rock instability is mainly the result of the combined action of energy dissipation and release. For the convenience of analysis, the work done by the floor on the coal body is ignored, and other energy losses such as acoustic emission and heat dissipation are not considered. Energy dissipation is mainly used to induce coal damage and destruction. And the energy release is mainly due to the sudden ejection of coal. Therefore, the occurrence of rock burst is essentially that the accumulated energy of coal and rock exceeds the sum of the two; that is, the calculation formula of the critical energy $E_{\min }$ for disaster occurrence is [19]

$$
E_{\text {min }}=W_{\text {min }}+U_{\text {min }},
$$

where $W_{\min }$ is the minimum energy for coal and rock mass destruction, J, and $U_{\min }$ is the coal and rock throwing work, $\mathrm{J}$ :

$$
\begin{aligned}
& W_{\text {min }}=\frac{\sigma_{c}^{2}}{2 E}, \\
& U_{\text {min }}=\frac{1}{2} \rho v_{\min },
\end{aligned}
$$

where $\sigma_{c}$ is the uniaxial compressive strength, $\mathrm{MPa} ; \rho$ is the average density of broken coal and rock mass, $\mathrm{kg} / \mathrm{m}^{3}$; and $v_{\min }$ is the minimum initial velocity of destruction of coal and rock mass, $\mathrm{m} / \mathrm{s}$. 


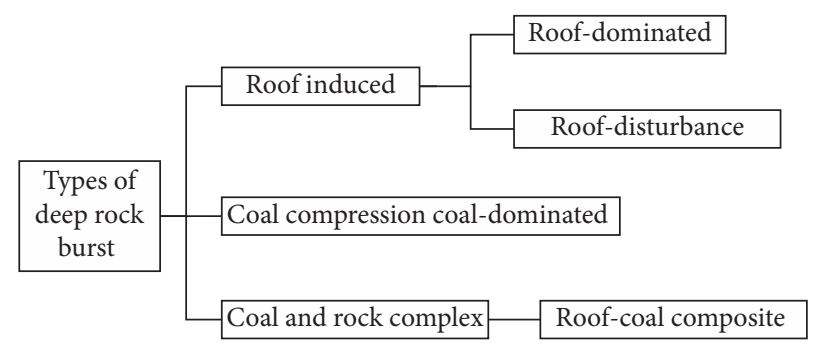

Figure 3: Types of deep rock burst.

Studies have shown that when the initial velocity is less than $1 \mathrm{~m} / \mathrm{s}$, it is impossible for rock burst to occur; when the initial velocity is not less than $10 \mathrm{~m} / \mathrm{s}$, the possibility of rock burst is greater.

Based on the above analysis, the energy condition for deep rock burst is

$$
E_{\min } \geq E_{d i}+E_{m}
$$

3.3. Research on Classification of Deep Rock Burst. Based on the theory of deep rock burst energy and according to the characteristics of the source and size of rock burst energy, the types of deep rock burst are accurately divided to understand the source mechanism of disaster occurrence, as shown in Figure 3, in order to provide a basis for improving the effectiveness and accuracy of the prevention and control of deep rock burst.

\section{Research on Construction of Prevention and Control System of Source of Deep Rock Burst}

4.1. Research on Different Criteria of Deep Rock Burst. As can be seen from Figure 3, based on the theory of deep rock burst energy, according to the relationship between roof breaking energy, coal body energy, and critical energy of disaster occurrence, deep rock burst is divided into three categories and four types. On this basis, the criteria for determining different attributes of deep rock burst are as follows.

4.1.1. Roof Induced. Roof induction is mainly caused by roof fracture. According to the magnitude of roof fracture energy, it can be divided into the following two situations:

(1) Roof-Dominated. When $E_{d}$ is greater than $E_{\min }$ and much greater than $E_{m}$ (according to Professor Zheng's research, the difference is at least 1 order of magnitude) [20], the "source" energy for the occurrence of deep rock burst comes from the roof fracture, which is called the roof-dominant type and can be expressed as

$$
\begin{array}{ll} 
& E_{d}+E_{m} \geq W_{\min }+U_{\min }, \\
& E_{d} \geq W_{\min }+U_{\min } \gg E_{m}, \\
\text { or } \quad & E_{d}+E_{m} \geq W_{\min }+U_{\min }, \\
& E_{d} \gg E_{m} \geq W_{\min }+U_{\min } .
\end{array}
$$

(2) Roof Disturbance. When $E_{m}$ is much greater than $E_{d}$ and both are greater than $E_{\min }$, the rock burst occurs under the influence of the shock wave disturbance caused by the roof fracture which is called the roof disturbance type and can be expressed as

$$
\begin{aligned}
& E_{m}+E_{d} \geq W_{\min }+U_{\min }, \\
& E_{m} \gg E_{d} \geq W_{\min }+U_{\min } .
\end{aligned}
$$

4.1.2. Coal Compression Type. When $E_{d}$ is less than $E_{\min }$ and far less than $E_{m}$, the "source" energy for the occurrence of rock burst comes from the coal body itself which is called coal compression type and can be expressed as

$$
\begin{aligned}
& E_{m}+E_{d} \geq W_{\min }+U_{\min }, \\
& E_{m} \geq W_{\min }+U_{\min } \gg E_{d} .
\end{aligned}
$$

4.1.3. Coal and Rock Complex. When there is not much difference from $E_{d}$ and $E_{m}$ and both are greater than $E_{\min }$, the "source" energy for the occurrence of rock burst comes from the double factors of roof fracture and coal itself that is called the coal and rock complex, which can be expressed as

$$
\begin{aligned}
E_{d}+E_{m} & \geq W_{\text {min }}+U_{\text {min }}, \\
E_{d}, E_{m} & \geq W_{\min }+U_{\text {min }}, \\
\text { or } \quad E_{d}+E_{m} & \geq W_{\min }+U_{\text {min }}, \\
E_{d}+E_{m} & \approx W_{\text {min }}+U_{\text {min }} .
\end{aligned}
$$

The above research provides a scientific basis for accurately determining the properties of deep rock burst and lays a theoretical foundation for the precise prevention and control of deep rock burst.

4.2. Construction of Accurate Prevention and Control System for Deep Rock Burst Disaster. By analyzing the mining current situation and existing prevention and control measures of the Chinese rock burst mines, the technologies were summarized related to rock burst monitoring, early warning, and prevention and control techniques. Early warning technology mainly includes microseismic monitoring, electromagnetic radiation monitoring, mining stress monitoring, and drill cutting method. Techniques for prevention and control mainly include coal seam water 
injection, pressure relief blasting, borehole pressure relief, and top breaking blasting.

According to the principle of "regional measures first, partial measures supplement" and the three categories and four types of properties of deep rock burst, combined with the actual production situation of Xin'an mine, different types of rock burst early warning and control measures are determined. In order to improve the accuracy of early warning of deep rock burst disasters, comprehensive judgments are made using working face monitoring (microseismic monitoring, electromagnetic radiation monitoring), local monitoring (mining stress monitoring), and point monitoring (drilling chip method) for effective control. These laid a solid foundation for effective control measures, specifically the following.

4.2.1. Roof Induced. Roof-dominated mainly adopts broken roof blasting, and, according to the relationship between the energy of the coal body and the critical energy, measures such as large-diameter borehole for pressure relief are selected to treat the coal body. Roof disturbance adopts measures such as large-diameter borehole pressure relief to treat coal and rock masses.

4.2.2. Coal Compression Type. For this type, measures such as large-diameter borehole for pressure relief and coal seam injection are used to treat the coal body.

4.2.3. Coal and Rock Complex. For this type, measures such as broken roof blasting, large-diameter borehole for pressure relief, and reduction in propulsion speed are adopted.

Based on the above, an accurate prevention and control system for the classification of rock burst in Xin'an Mine is established, as shown in Figure 4.

\section{Engineering Application Effect Evaluation}

5.1. Judgment of Disaster Attributes in the Rock Burst Dangerous Area of Working Face. According to the dangerous area divided by the working face and the guide of energy mechanism of deep rock burst, combined with geological conditions, the types of disasters occurring in different areas of the working face are determined to provide a basis for effective early warning and prevention of rock burst.

5.1.1. Calculation of Critical Energy for Rock Burst. According to formula (5), taking $\sigma_{c}=11.06 \mathrm{MPa}, E=20 \mathrm{GPa}$, $W_{m 1}=1337 \mathrm{~kg} / \mathrm{m}^{3}, \quad v_{\min }=10 \mathrm{~m} / \mathrm{s}$, getting $W_{\min }=2.86 \times$ $10^{4} \mathrm{~J} / \mathrm{m}^{3}, \quad U_{\min }=6.74 \times 10^{4} \mathrm{~J} / \mathrm{m}^{3}$, therefore, $\quad E_{\min }=9.60 \times$ $10^{4} \mathrm{~J} / \mathrm{m}^{3}$.

\subsubsection{Calculation of Critical Energy for Rock Burst}

(1) Transfer Characteristics of Roof Broken Energy. According to formulas (1) and (2), taking $K=1.14, \eta=0.1, \lambda=1.5$, the energy transmitted by the broken roof to the working surface is calculated; see Table 1 .

The energy transmitted to the working face from the initial breakage of the key layer 1 is $2.95 \times 10^{5} \mathrm{~J} / \mathrm{m}^{3}$, which is greater than the critical energy. Therefore, the initial breakage of the key layer 1 may induce rock burst. The periodic breakage energy of the key layer 1 is much smaller than the critical energy, and it could not cause rock burst. The energy transmitted to the working face at the initial breakage and periodic breakage of the key layer 2 is far less than the critical energy. It is determined that the breakage of the key layer 2 could not cause dynamic disasters.

(2) Coal Body Energy Calculation. According to formula (3) and the results of in situ stress test, taking $\sigma_{1}=38.81 \mathrm{MPa}$, $\sigma_{2}=20.15 \mathrm{MPa}, \sigma_{3}=17.10 \mathrm{MPa}, \mu=0.25$, and $E=25 \mathrm{GPa}$. The energy density is calculated to be $5.23 \times 10^{4} \mathrm{~J} / \mathrm{m}^{3}$.

Comprehensive energy source calculation value, roof breaking energy $>$ critical value $>$ coal energy: it is determined that in the normal mining process, Areas 1, 2, and 4 are roof-dominated. Area 3 is affected by the fold structure and the mining conditions are complex, so it is treated as a composite type of coal and rock.

\subsection{Effect Analysis of Accurate Prevention and Control System for Classification of Rock Burst in Xin'an Mine}

5.2.1. Analysis of Measures for Controlling Rock Burst in Working Face. According to the precise prevention and control system for the source of rock burst in Xin'an Mine, the broken roof blasting measures are adopted for dangerous area 1, the large-diameter borehole for pressure relief is used in Areas 2 and 4, and the large-diameter borehole for pressure relief, reduction in propulsion speed, and so forth is used in coal and rock bodies, as shown in Figure 5.

\subsubsection{Application Effect Evaluation}

(1) Microseismic Monitoring. The working face adopts BMS microseismic monitoring and positioning analysis system to statistically analyze the microseismic conditions occurring during mining.

It can be seen from Table 2 that the energy and magnitude of microseisms are small during the propulsion of the working face, and the location of the occurrence is a certain distance away from the working face. Generally, it has no effect on the working surface, and there are three times that it slightly damages the roof support in front of the air inlet tunnel.

(2) Electromagnetic Radiation Monitoring. The KBD7 electromagnetic radiation monitor (online) is used for real-time monitoring of the working surface, and the layout interval is $50 \mathrm{~m}$ to ensure that the coal body stress change within $50 \mathrm{~m}$ of the working face is in real-time monitoring. The results are shown in Figure 6. 


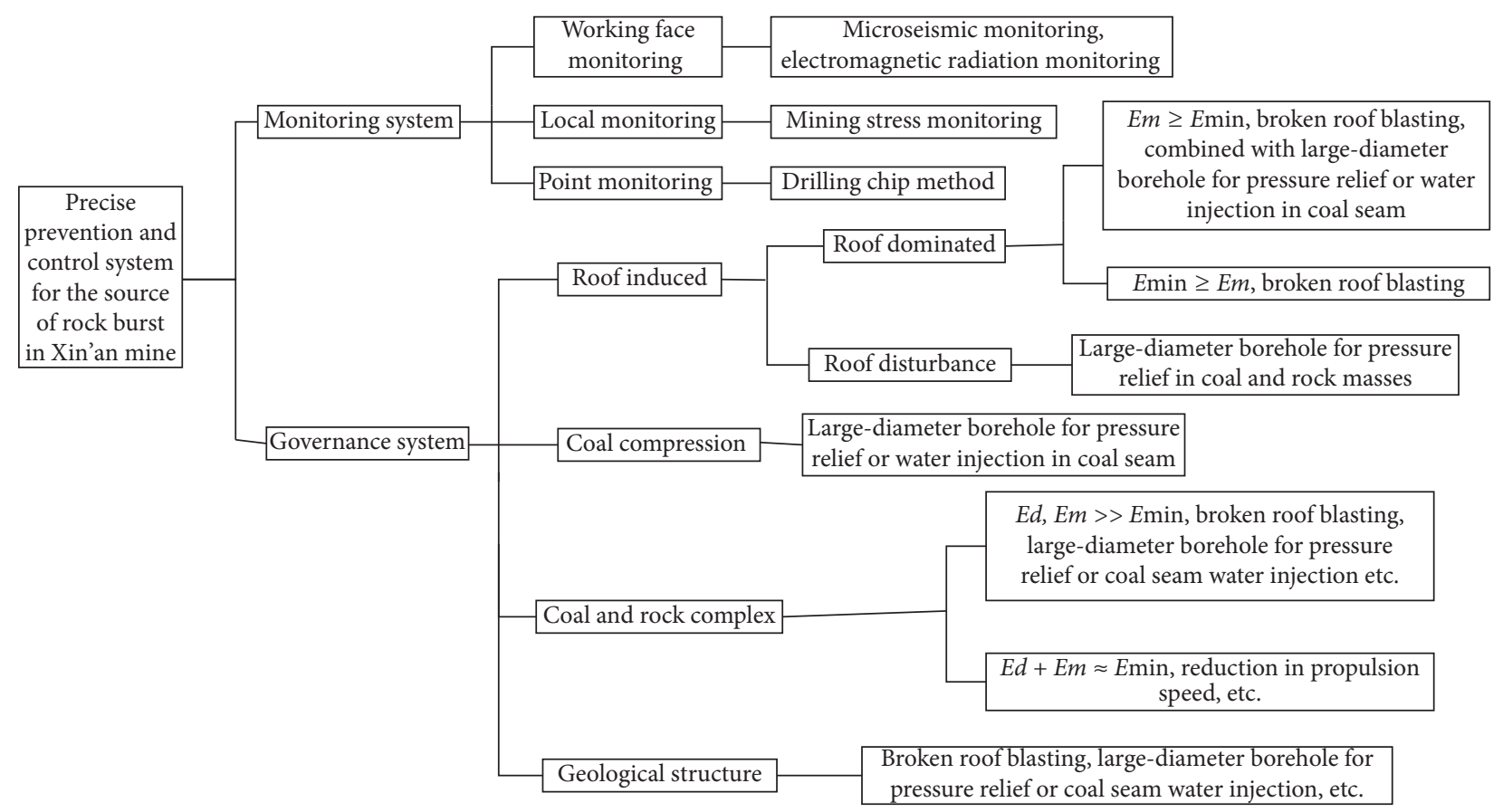

FIGURE 4: Construction of precise prevention and control system for the source of rock burst in Xin'an mine.

TABLe 1: Calculation of the energy transfer from the roof rock to the working face.

\begin{tabular}{|c|c|c|c|c|}
\hline \multirow{2}{*}{ Name } & \multicolumn{2}{|r|}{ Initial breakage } & \multicolumn{2}{|r|}{ Period breakage } \\
\hline & Distance $(\mathrm{m})$ & Energy transferred to the working face $\left(\mathrm{J} \cdot \mathrm{m}^{-3}\right)$ & Distance $(\mathrm{m})$ & Energy transferred to the working face $\left(\mathrm{J} \cdot \mathrm{m}^{-3}\right)$ \\
\hline Key layer 1 & 31.98 & $2.95 \times 10^{5}$ & 13.21 & $5.91 \times 10^{3}$ \\
\hline Key layer 2 & 39.07 & $1.36 \times 10^{4}$ & 15.95 & $0.17 \times 10^{3}$ \\
\hline
\end{tabular}

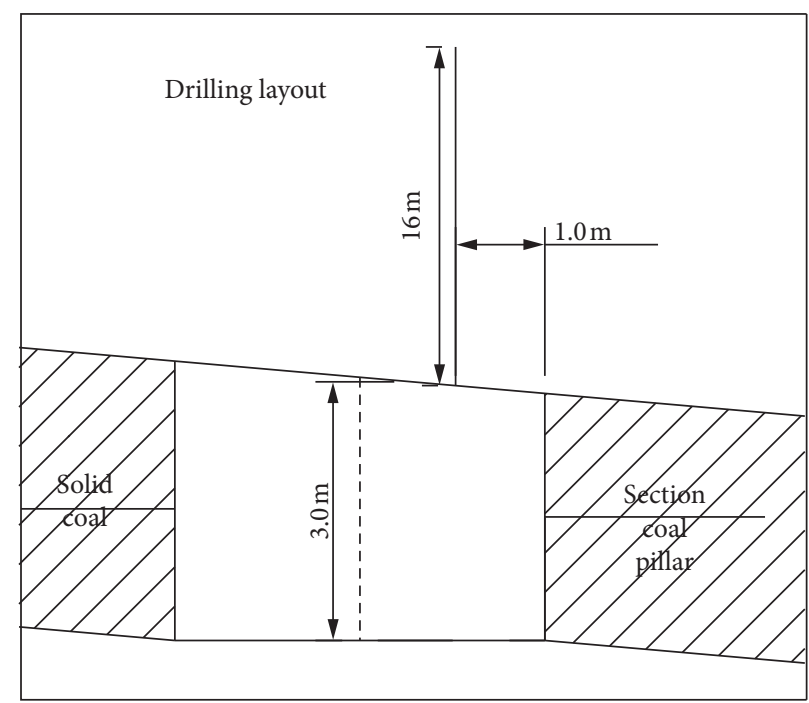

FIGURE 5: Diagram of rock burst management in LW 8101.

It can be seen from Figure 6 that from $22^{\text {nd }}$ to $24^{\text {th }}$ of October, mainly due to the influence of the period pressure and the position of square stage of the working face, the monitoring data is relatively large; from $2^{\text {nd }}$ to $5^{\text {th }}$ of December and $13^{\text {th }}$ to $14^{\text {th }}$ of December, the monitoring data shows an upward trend because the working face was mining in the secondary square area and in the structural area of the syncline axis. Therefore, it is necessary to strengthen the observation and the broken roof blasting to control the roof when necessary. 
TABLe 2: Microseismic occurrence.

\begin{tabular}{|c|c|c|}
\hline Time & Magnitude & Position \\
\hline 1st Sept. & 1.39 & Behind the goaf \\
\hline 5th Sept. & 1.07 & Slant axis in transport lane \\
\hline 22th Sept. & 1.34 & Slant axis \\
\hline 14th Oct. & 0.93 & The back goaf $100 \mathrm{~m}$ to the right and $80 \mathrm{~m}$ below the eighth coal seam, which has no effect on the working face \\
\hline 18th Oct. & 0.68 & A slight damage to the roof support in front of the air inlet tunnel \\
\hline 20th Oct. & 0.7 & Outside roadway \\
\hline 23th Oct. & 0.71 & The slant axis of the eighth coal seam outside the air inlet and return roadway \\
\hline 24th Oct. & 0.85 & Near the fault of the stop line outside the working face \\
\hline 25th Oct. & 0.86 & Outside of working face (uphill side) \\
\hline 10th Dec. & 0.66 & Track lane of the eighth coal seam \\
\hline 11th Dec. & 1.1 & $200 \mathrm{~m}$ below the eighth coal seam at the edge of the back goaf \\
\hline 12th Dec. & 0.77 & A slight damage to the roof support in front of the air inlet tunnel \\
\hline 12th Dec. & 0.81 & A slight damage to the roof support in front of the air inlet tunnel \\
\hline 15th Dec. & 0.79 & Intersection outside the return airway \\
\hline
\end{tabular}

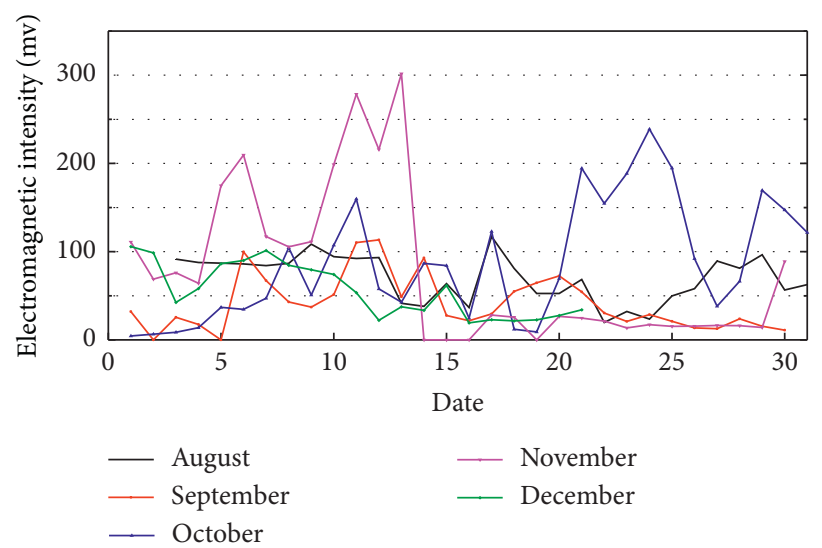

FIgURE 6: Variation of electromagnetic radiation intensity.

TABle 3: Drill cuttings experimental data statistics table.

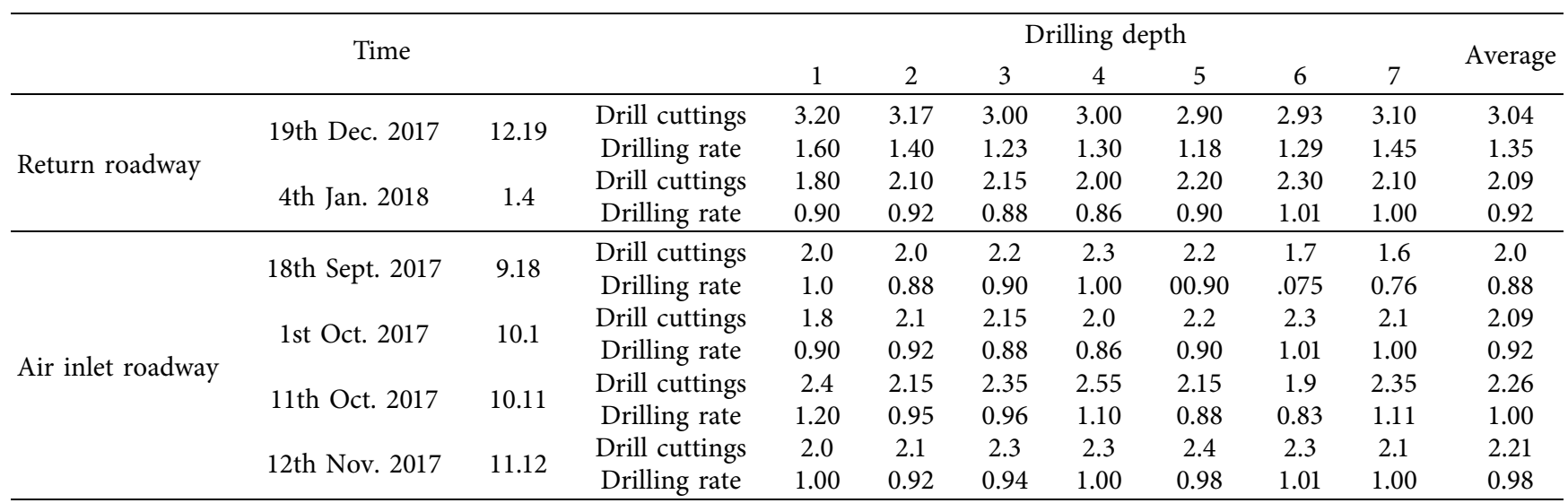

(3) Drilling Cutting Method. The drill cuttings method is an effective auxiliary method, which is very important for further confirming the risk and checking the effect of eliminating the danger of rock burst. During the mining of the working face, the drill cuttings method is used to assist. The experimental data is shown in Table 3.
From Table 3, on the side of the air inlet roadway, there is no significant change in the load of the coal's own stress field under the influence of mining disturbance and external factors, so the stress value of the measured coal body is not high. On the side of the return roadway, the amount of drill cutting and drilling powder rate of the coal body's 
own stress field at the measured location has increased under the influence of mining disturbance and a series of external factors on $19^{\text {th }}$ of December. This data was consistent with the increase in the maximum and average values of KBD-7 electromagnetic radiation monitoring data, but it still did not exceed the critical drilling powder amount of 3.38. Therefore, the occurrence of rock burst is unlikely, and engineering practice shows that it has good reliability.

In summary, Xin'an Mine successfully applied the precise prevention and control system of rock burst source and achieved remarkable results. It not only guarantees safe production on the working face and reduces labor intensity, but also improves the effectiveness and accuracy of disaster prevention and control and achieves good social and economic benefits.

\section{Conclusions}

(1) According to the characteristics of deep mining, the coal and rock mass multisource energy unified equation is established to analyze the coal and rock mass instability mechanism. The types of deep rock burst are determined as three categories and four types based on the different degrees of participation of various factors, and the corresponding criteria are proposed.

(2) Combining with the mining characteristics of Xin'an Mine, targeted prevention and control measures were proposed for different disaster attributes. And the precise prevention and control system for the source of rock burst with Xin'an characteristics has been proposed to improve the reliability and accuracy of engineering applications.

(3) The research results are applied to the 8101 face of Xin'an Coal Mine, which not only achieves the purpose of safe production, but also has direct economic benefits. It can provide a reference for the prevention and treatment of mines similar to deep rock burst.

\section{Symbols}

$L_{1}: \quad$ The first breakage step $(\mathrm{m})$

$L_{2}: \quad$ The periodic breakage step $(\mathrm{m})$

$q_{0}$ : The load evenly distributed above the rock (MPa)

$E: \quad$ The elastic modulus (MPa)

$h_{1}$ : The thickness of coal $(\mathrm{m})$

$h_{2}$ : The thickness of rock layer between coal and key layer $(\mathrm{m})$

$h_{3}$ : The thickness of rock layer (m)

$h_{4}$ : The thickness of upper following rock layer $(\mathrm{m})$

$\rho_{3}$ : The density of rock layer $\left(\mathrm{kg} \cdot \mathrm{m}^{-3}\right)$

$\rho_{4}$ : The density of upper following rock layer $\left(\mathrm{kg} \cdot \mathrm{m}^{-3}\right)$

K: $\quad$ The rock fragmentation expansion coefficient

$\eta: \quad$ The ratio of vibration energy to total energy

$l: \quad$ The distance from source to working surface $(\mathrm{m})$

$\lambda: \quad$ The energy attenuation coefficient

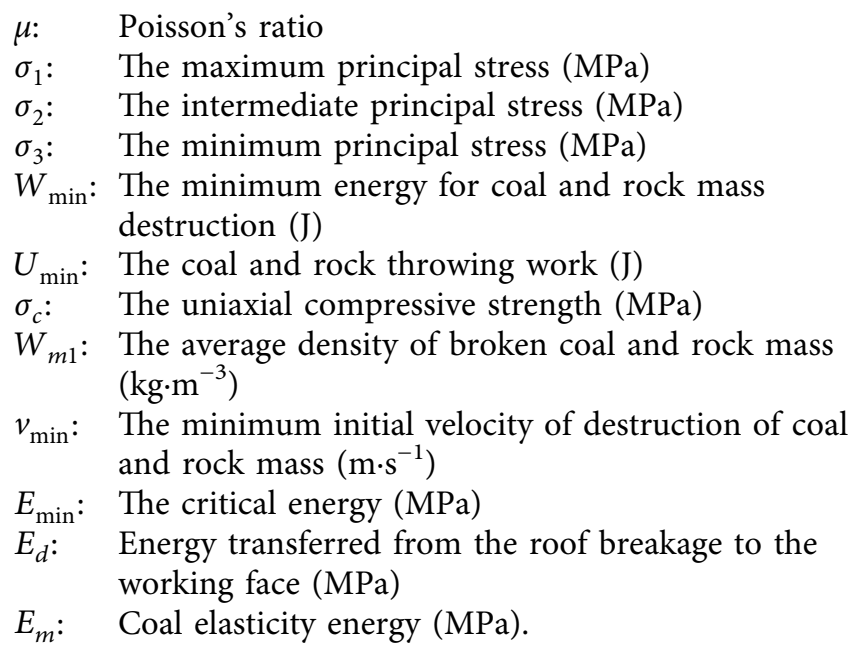

\section{Data Availability}

The data of this study are available from the corresponding author upon request.

\section{Conflicts of Interest}

The authors declare that they have no conflicts of interest. All the authors approved to submit the paper.

\section{References}

[1] H. Li, H. Bai, J. Wu et al., "Mechanism of water inrush driven by grouting and control measures-a case study of Chensilou mine China," Arabian Journal of Geosciences, vol. 10, no. 21, 2017.

[2] D. Qian, N. Zhang, M. Zhang et al., "Application and evaluation of ground surface pre-grouting reinforcement for 800m-deep underground opening through large fault zones," Arabian Journal of Geosciences, vol. 10, no. 13, 2017.

[3] W. Gao, L. Shi, J. Han et al., "Study on control water of Ordovician aquifer: a coal mine of Feicheng mining area," China. Carbonates Evaporites, vol. 35, no. 48, 2020, https:// doi.org/10.1007/s13146-020-00588-3.

[4] Y. Jiang, Y. Pan, F. Jiang et al., "State of the art review on mechanism and prevention of coal bumps in China," Journal of China Coal Society, vol. 39, no. 2, pp. 205-213, 2014, in Chinese.

[5] F. Jiang, Y. Liu, M. Zhai et al., "Evaluation of rock burst hazard based on the classification of stress and surrounding rock," Chinese Journal of Rock Mechanics and Engineering, vol. 36, no. 5, pp. 1041-1052, 2017, in Chinese.

[6] M. Zhai, F. Jiang, Q. Qi et al., "Research and practice of rock burst classified control system," Journal of China Coal Society, vol. 42, no. 12, pp. 3116-3124, 2017, in Chinese.

[7] J. Pan, Q. Qi, S. Liu et al., "Characteristics, types and prevention and control technology of rock burst in deep coal mining in China," Journal of China Coal Society, vol. 45, no. 1, pp. 111-121, 2020, in Chinese.

[8] J. Kabiesz, A. Lurka, and J. Drzewiecki, "Selected methods of rock structure disintegration to control mining hazards/ wybrane metody dezintegracji struktury skał dla zwalczania zagrożeń górniczych," Archives of Mining Sciences, vol. 60, no. 3, pp. 807-824, 2015. 
[9] A. T. Iannacchione and S. C. Tadolini, "Occurrence, predication, and control of coal burst events in the U.S," International Journal of Mining Science and Technology, vol. 26, no. 1, pp. 39-46, 2016.

[10] P. Konicek, K. Soucek, L. Stas, and R. Singh, "Long-hole destress blasting for rockburst control during deep underground coal mining," International Journal of Rock Mechanics and Mining Sciences, vol. 61, pp. 141-153, 2013.

[11] W. Miroslaw and M. Mariusz, "Structural aspects of gas and dolomite outburst in Rudna copper mine, Poland," International Journal of Rock Mechanics and Mining Sciences, vol. 57, pp. 113-118, 2013.

[12] Z. Mu, L. Dou, H. He, and J. Fan, "F-structure model of overlying strata for dynamic disaster prevention in coal mine," International Journal of Mining Science and Technology, vol. 23, no. 4, pp. 513-519, 2013.

[13] S. Dehghan, K. Shahriar, P. Maarefvand, and K. Goshtasbi, "3D modeling of rock burst in pillar No. 19 of Fetr6 chromite mine," International Journal of Mining Science and Technology, vol. 23, no. 2, pp. 231-236, 2013.

[14] A. C. Adoko, C. Gokceoglu, L. Wu, and Q. J. Zuo, "Knowledge-based and data-driven fuzzy modeling for rockburst prediction," International Journal of Rock Mechanics and Mining Sciences, vol. 61, pp. 86-95, 2013.

[15] H. He, L. Dou, J. Fan, T. Du, and X. Sun, "Deep-hole directional fracturing of thick hard roof for rockburst prevention," Tunnelling and Underground Space Technology, vol. 32, pp. 34-43, 2012.

[16] J. Kornowski and J. Kurzeja, "Prediction of rockburst probability given seismic energy and factors defined by the expert method of hazard evaluation (MRG)," Acta Geophysica, vol. 60, no. 2, pp. 472-486, 2012.

[17] Z. Zhu, "Hard roof movement feature and fully mechanized top-coal caving face's influence on strata behavior in datong mining area," Ph.D. thesis. in Chinese, Liaoning Technical University, Fuxin, China, 2015, in chinese.

[18] Q. Hu, "Mechanical mechanism of coal and gas outburst process," Ph.D. thesis. in Chinese, China University of Mining and Technology, Beijing, China, 2007, in Chinese.

[19] Z. Gao, "Study on the coupling law and prediction technology of mining impact and outburst danger in isolated island," Ph.D. thesis in Chinese, China University of Mining and Technology, Beijing, China, 2011, in Chinese.

[20] Z. Zheng, "Viewing the mechanism of coal and gas outburst from the analysis of order of magnitude and dimension," Anthology of Zheng Zhemin, 2004, in Chinese. 